\title{
Semiótica e Design de Informação: uma experiência didática de metadiciplina
}

\author{
Semiotics and Information Design: a didactic experience of metadiscipline
}

\author{
Anna Lúcia dos Santos Vieira e Silva; Alexander Catunda Carneiro; Lya Brasil Calvet; \\ José Rondney da Silva Mendonça
}

semiótica, metadisciplina, design de informação, didática

\begin{abstract}
O objetivo deste artigo é apresentar a Semiótica e o Design de Informação no contexto de uma experiência didática e de pesquisa realizadas no curso de Design da Universidade Federal do Ceará. A experiência analisada se refere à aplicação do Design de Informação na disciplina de Semiótica e na pesquisa "Metadisciplina: um enfoque semiótico". O sentido de metadisciplina abrange a construção participativa da disciplina, o uso da Semiótica de Peirce e do design da informação como conteúdo e ferramenta de estruturação das informações sobre a própria semiótica. A metodologia empregada aplica os fundamentos da pesquisa no intuito de flexibilizar os papéis professor-aluno-monitor e garantir que os saberes pessoais sejam agregados ao processo de aprendizagem, construção e troca de conhecimentos de forma participativa. Ainda que a pesquisa esteja em andamento, a disciplina concluída em 2017 oferece parâmetros e elementos de análise do processo de compreensão e transmissão das informações adquiridas, cuja abordagem em sala de aula inclui em seus resultados a produção de infográficos elaborados pelos estudantes.
\end{abstract}

semiotics, metadiscipline, information design, didactics

The purpose of this article is to present Semiotics and Information Design within the context of a didactic and research experience conducted in the Design program of the Federal University of Ceará. The analyzed experiment regards the application of information design in the Semiotics course and in the research project "Metadiscipline: a semiotic focus". The metadiscipline's essence accomodates the participatory development of the course and the use of Peirce's Semiotics and information design as content and as a tool for structuring the information which concerns semiotics itself. The methodology applied in the course uses the research's basis in order to flexibilize the teacher-student-assistant roles and to assure the personal knowledge is affiliated to the process of learning, construction and knowledge exchange in a participatory way. Although the research is in progress, the finished course in 2017 offers parameters and analysis elements to the process of comprehension and transmission of acquired information, which the approach in the classroom includes, in its results, the production of infographics elaborated by the students.

\section{Introdução}

O projeto de pesquisa "Metadisciplina: um enfoque semiótico" tem início em 2017 na Universidade Federal do Ceará (UFC), com o objetivo principal de ampliar conhecimentos sobre os processos de ensino e de aprendizagem na confluência das áreas da pedagogia, semiótica, arquitetura e design. Como uma pesquisa interdisciplinar, o projeto se justifica por sua relevância em organizar e analisar saberes educacionais capazes de aperfeiçoar a atuação docente e expandir as perspectivas do protagonismo discente em processos criativos e na produção de conhecimento. A metadisciplina se constrói enquanto é ministrada e, ainda que cumpra com os objetivos da ementa, os métodos e a estrutura curricular são decididos e desenvolvidos ao longo do processo pedagógico, com os estudantes, de forma participativa (Tripp, 2005; Toledo \& Jacobi, 2013).

Torres (2004: 50) apresenta a proposta colaborativa como a que implica a participação ativa do aluno no processo de aprendizagem; a construção coletiva do conhecimento, que

Anais do 8 CIDI e 8 CONGIC

Guilherme Santa Rosa; Cristina Portugal (orgs.)

Sociedade Brasileira de Design da Informação - SBDI

Natal | Brasil | 2017

ISBN 978-85-212-1305-5
Proceedings of the $8^{\text {th }}$ CIDI and $8^{\text {th }}$ CONGIC

Guilherme Santa Rosa; Cristina Portugal (orgs.)

Sociedade Brasileira de Design da Informação - SBDI

Natal| Brazil | 2017

ISBN 978-85-212-1305-5 
emerge da troca entre pares, das atividades práticas dos alunos, de suas reflexões, de seus debates e questionamentos; mediação da aprendizagem por professores, tutores e monitores; interatividade entre os diversos atores que atuam no processo; estimulação dos processos de expressão e comunicação; flexibilização dos papéis no processo das comunicações e das relações a fim de permitir a construção coletiva do saber; sistematização do planejamento, do desenvolvimento e da avaliação das atividades; aceitação das diversidades e diferenças entre alunos; desenvolvimento da autonomia do aluno no processo ensino-aprendizagem; valorização da liberdade com responsabilidade; comprometimento com a autoria; maior valorização do processo que do produto.

A metadisciplina é aplicada no Departamento de Arquitetura e Urbanismo, no curso de Design desde 2014, por influência da proposta pedagógica da disciplina "Didática I" (2014.2), da Faculdade de Educação, assistida por uma professora do curso de design e aplicada nas disciplinas "Métodos de Representação" (2014.2); "Semiótica" (2015.1, 2016.1 e 2017.1) e "Projeto de Produto IV" (2015.2 e 2016.2), todas do curso de Design da UFC. Por seus resultados, alguns artigos científicos já foram publicados, mas é necessário um aprofundamento investigativo no que diz respeito aos processos de construção de significados (semiose). O relato e análise desta experiência didática aborda o processo da disciplina de Semiótica enquanto metadisciplina no semestre de 2017.1. A escolha em explorar esta aplicação se deve principalmente ao envolvimento dos coautores com a pesquisa, além de serem monitores da disciplina em questão e especialmente por um certo amadurecimento da metodologia em sua terceira aplicação.

A Semiótica de Peirce é abordada na disciplina por meio de três módulos. O primeiro consiste na apresentação da teoria geral dos signos e culmina na produção de um infográfico de conteúdos semióticos; o segundo aborda a semiose e compreende o ato projetual como um processo sígnico, cujo produto é definido de acordo com as iniciativas e escolhas dos alunos; 0 terceiro, uma análise semiótica. O Design de Informação tem como objetivo apresentar e organizar dados, transformando-os em informação com valores e sentidos (Shedroff, 2000; Frascara, 2004, 2011). Na disciplina, ele oferece a estrutura necessária para fundamentar a forma como o conteúdo é apropriado, elaborado e transmitido pelos estudantes. Como o primeiro módulo trabalha com a produção de infográficos, este passa a ser o objeto de investigação do presente artigo, uma vez que as relações entre semiótica, design de informação e metadisciplina são enfatizadas na produção da peça gráfica, cujos procedimentos e resultados são analisados.

\section{Primeiridade: Conteúdo, um infinito de possibilidades}

O primeiro aspecto trabalhado na disciplina antes do início das aulas, entre a professora e os três monitores voluntários que haviam experienciado a metadisciplina no ano anterior, é o exercício de selecionar alguns conteúdos relativos à semiótica e pertinentes à área de conhecimento do design, sem que essa seleção impeça ou limite os infinitos conteúdos dos repertórios individuais e de interesse dos estudantes. Como trazer uma informação específica se propomos construir juntos o universo de informações? Partimos, então, de dois pressupostos:

"[...] a semiótica não é uma chave que abre para nós milagrosamente as portas de processos de signos cuja teoria e prática desconhecemos. Ela funciona como um mapa lógico que traça as linhas dos diferentes aspectos através dos quais uma análise deve ser conduzida, mas não nos traz nenhum conhecimento específico da história, teoria e prática de um determinado processo de signos. Sem conhecer a história de um sistema de signos e do contexto sociocultural em 
que ele se situa, não se pode detectar as marcas que o contexto deixa na mensagem." (Santaella, 2008: 6)

"Pela qualidade, tudo pode ser signo, pela existência, tudo é signo, e pela lei, tudo deve ser signo." (Santaella, 2008: 12)

Assim, o início da aula é pensado como uma série de perguntas capazes de trazer os princípios da significação e, no processo, os fundamentos da semiótica.

\subsection{O que é semiótica?}

O plano inicial é de confrontar os alunos com questões abrangentes: O que é real? A intenção é impactá-los ao serem recebidos com uma pergunta deste tipo já no primeiro momento da disciplina, sem que tenham recebido nenhum conteúdo prévio e, muitas vezes, sem saber do que se trata exatamente a disciplina. Assim, os alunos são convidados a saírem da zona de conforto, deixando uma posição de receptores passivos para o lugar de contribuintes ativos e pensantes no ambiente da sala de aula.

Após um período de discussão sobre a primeira pergunta, são colocadas para os alunos duas novas questões: O que é signo e o que é semiótica? O objetivo dessas questões é expandir o nível de pensamento dos alunos, prepará-los para adentrar uma experiência de aprendizagem que exige uma racionalização filosófica em todas as aulas.

\subsection{Conteúdo teórico e bibliografia}

"Diferentemente de uma ciência especial, a semiótica de Peirce é uma das disciplinas que compõem uma ampla arquitetura filosófica concebida como ciência com um caráter extremamente geral e abstrato. Ela é um dos membros da tríade das ciências normativas - estética, ética e lógica ou semiótica -, estas antecedidas pela quase-ciência da fenomenologia e seguidas pela metafísica." (Santaella, 2008: XII)

Semiótica é a teoria geral dos signos. Tanto a palavra semiótica quanto a palavra signo

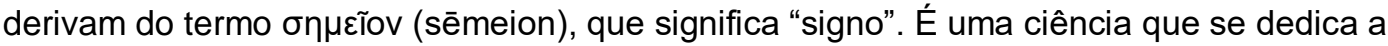
estudar os fenômenos de significação. $O$ termo foi usado pela primeira vez pelo britânico Henry Stubbes (1670) para se referir a um ramo da ciência médica que estuda a interpretação de sinais. Em síntese, a semiótica é um processo metodológico-analítico, que permite analisar as diferentes naturezas que um signo possa ter, bem como suas referências e suas aplicabilidades, analisando também o impacto que essa cadeia de significados causa em seus receptores (Santaella, 2002: 2-4).

A semiótica é dividida em duas principais vertentes. Costuma-se chamar de "semiótica" a teoria geral dos signos, que é a vertente iniciada nos Estados Unidos por Charles Sanders Peirce (1839 - 1914) e de "semiologia" a vertente européia, que surge de forma independente da primeira e possui metodologias e abordagens diferentes. Enquanto a primeira abrange todas as linguagens, a segunda se aprofunda na linguagem verbal. "É em razão disso que venho chamando as semióticas não peirceanas de semióticas especiais, pois se trata de semióticas especializadas." (Santaella, 2008: XV)

Sempre partindo das relações triádicas de Peirce, signo/objeto/interpretante e as categorias fenomenológicas primeiridade/secundidade/terceiridade são as hélices que movimentam nossas intenções para as primeiras aulas. 


\subsection{Seleção de conteúdo}

Na disciplina, foram propostas duas bibliografias fundamentais, uma que concentra os fundamentos da semiótica: Semiótica Aplicada (Santaella, 2008) e Elementos de Semiótica Aplicados ao Design (Niemeyer, 2007).

Santaella traz os fundamentos da semiótica e mostra os conceitos de signo, objeto e interpretante e suas respectivas subdivisões, assim como as categorias fenomenológicas: primeiridade, secundidade e terceiridade.

"O signo é qualquer coisa de qualquer espécie (uma palavra, um livro, uma biblioteca, um grito, uma pintura, um museu, uma pessoa, uma mancha de tinta, um vídeo etc.) que representa uma outra coisa, chamada de objeto do signo, e que produz um efeito interpretativo em uma mente real ou potencial, efeito este que é chamado de interpretante do signo." (Santaella, 2008: 8)

A semiótica peirceana caracteriza-se por ser fundamentada em tríades conceituais, sendo signo/objeto/interpretante a principal dessas tríades. O signo é algo, de qualquer natureza, com o poder de representar algo, este algo sendo o objeto deste signo e o efeito causado em um receptor sendo o seu interpretante.

O signo é um primeiro que se refere a um segundo (objeto) e que nos leva a um terceiro (interpretante) (Santaella, 2008: 7). Esta lógica já nos leva ao próximo tópico discutido em aula: as categorias fenomenológicas.

Fenômeno é tudo aquilo que é percebido, que chega a nossa mente. A fenomenologia tem por objetivo categorizar todos os modos com que estes fenômenos chegam a nossa percepção.

Seguindo a lógica triádica, Peirce chega à conclusão de que existem três modos de percepção dos fenômenos: primeiridade, secundidade e terceiridade. A primeiridade está no campo das infinitas possibilidades, logo se encontra nela tudo o que é acaso, sentimento, liberdade. A secundidade está no campo da existência, da materialização, e nela se encontra tudo o que é imediato, espontâneo, aqui e agora. A terceiridade está no campo da lei, e tudo o que remete à interpretação, continuação, evolução, entendimento, compreensão (Santaella, 2008: 7).

Após entendermos isso, nos aprofundamos nos conceitos de signo, objeto e interpretante, bem como suas subdivisões:

Signo em relação a ele mesmo

1. Quali-signo: Uma qualidade pura, que por si só já possui certa carga interpretativa e que pouco caracteriza o objeto. Uma cor, uma textura, um som.

2. Sinsigno: Já é um aspecto do signo que o caracteriza, que o identifica, como o formato e dimensões de algo existente.

3. Legisigno: Uma regra, um signo definido por uma convenção, como o vermelho de um semáforo que convencionalmente indica ao motorista que ele deve parar. (Niemeyer, 2007: 39)

Signo em relação ao objeto 
1. Ícone: É um signo que carrega semelhança com o objeto. Ele parece na sua forma o objeto que representa, como pictogramas de banheiros.

2. Índice: É um signo que indica a presença do objeto, uma marca causada por este, como as pegadas de um cão (sendo o objeto o cão).

3. Símbolo: É um signo estabelecido por convenção; ele não obrigatoriamente tem uma relação icônica nem indicial com o objeto, mas faz referência, pois foi condicionado a isso (uma norma). Como, por exemplo, o pedigree de um cão. (Niemeyer, 2007: 40-41)

Signo em relação ao interpretante:

1. Rema: É um signo de possibilidades em terceiridade, amplo e impreciso. Possui e carrega uma gama de possíveis interpretações, como a palavra "vermelho".

2. Dicente: É quando o interpretante particulariza o signo. O signo traz uma característica de existencia,como a frase "o vermelho desta maçã".

3. Argumento: É quando o interpretante está completamente seguro de sua interpretação. Há nele um caráter de certeza absoluta, irrevogável, uma lei. Como, por exemplo, a premissa "toda macieira dá maçãs". (Niemeyer, 2007: 43)

Concluímos a fase de conteúdo e bibliografia e passamos a um novo momento na disciplina, em que começamos a criar nossos próprios signos, com o conteúdo aprendido, no intuito de reforçar e fixar a teoria. Os procedimentos aplicados nesse processo é o que vemos a seguir.

\section{Secundidade: hic et nunc - Método}

O segundo aspecto a ser abordado é a própria maneira como as aulas são conduzidas e as interações da turma em relação à metodologia planejada por professora e monitores. É o aqui e agora, o encontro entre o conteúdo previamente elaborado e as vivências particulares dos alunos.

\subsection{Proposição da metadisciplina aos alunos}

Com a estrutura das aulas organizada pela equipe de professora e monitores, é realizada a proposição da metadisciplina para os alunos. Uma vez que esta é fundamentada na colaboração (Torres, 2004), faz-se necessário investigar se os discentes se interessam e de fato aceitam a metodologia em questão. Com a aceitação da proposta, mesmo que parte da turma ainda não entenda muito bem o que é uma metadisciplina, o processo é continuado.

\subsection{Objeto infinito: cadeira}

Em um primeiro momento, o conteúdo da disciplina é introduzido de forma aberta, mais abrangente, sem ainda citar nomenclaturas ou classificações. $O$ aprendizado horizontal, característico da metadisciplina, é evidenciado na disposição da sala de aula, onde as cadeiras são dispostas em roda, o que retira a hierarquia do espaço didático onde todos estão voltados para o professor e encoraja os discentes a debaterem entre si e incorporar suas próprias vivências e opiniões aos conteúdos propostos pelos monitores e professora.

Como ponto de partida para o entendimento da teoria, é realizada uma dinâmica que visa explicar, de modo prático, os conceitos iniciais que guiam a semiótica peirceana. A 
professora elege uma cadeira, um objeto cotidiano, que é colocado no centro da roda, como objeto de análise. É solicitado que os alunos façam representações da cadeira da forma que preferirem, o que inclui desenhos, fotografias, poemas etc. Ao final da dinâmica se tem, naturalmente, representações extremamente diversificadas. Esta atividade funciona como o mote para a primeira conceituação, em sala, do signo dentro do contexto da semiótica Peirceana.

Com estes conceitos em mente, os alunos são orientados a trazerem, na aula seguinte, objetos que os representem. É realizada, então, uma nova dinâmica, em que o motivo das escolhas não é revelado por quem trouxe o objeto e os colegas devem decifrar o significado "Por que este objeto representa esta pessoa?" valendo-se de referenciais prévios.

\subsection{Introdução da bibliografia}

Com a dinâmica, é possível dizer que a compreensão do que é signo é fortalecida e, assim, pode-se introduzir as nomenclaturas que sustentam a teoria. Os monitores selecionam, para leitura, o capítulo 5 do livro Elementos de Semiótica Aplicados ao Design, de Lucy Niemeyer (2007), a fim de legitimar as atividades anteriores. Para a leitura do texto, os alunos dividem-se em grupos de cinco a seis membros, nos quais certos questionamentos são suscitados. Após o momento da leitura, os monitores fazem uma síntese do conteúdo exposto através do texto e incitam os alunos a tirarem dúvidas. Nesta etapa, são introduzidas as tríades básicas da semiótica Perceiana: a das categorias fenomenológicas (primeiridade, secundidade e terceiridade) e a do processo de semiose (signo, objeto e interpretante).

\section{Terceiridade: Resultado, avaliação, decodificação}

Após os alunos aceitarem a aplicação da metadisciplina como estrutura para as aulas e de uma fase de assentamento e apresentação primária do conteúdo, é tomado o início da elaboração deste para um entendimento racional e categorizado do tema abordado, Se inicia, então, o primeiro passo para a solidificação do conhecimento e a tradução posterior de tal conhecimento para a produção do resultado final: o infográfico.

\subsection{Roda Muda}

A fase de estruturação se inicia com uma dinâmica, a "Roda Muda". Os alunos se organizam em roda e discutem sobre os conceitos, categorias e nomenclaturas abordados nos textos lidos previamente, enquanto professora e monitores permanecem calados, podendo intervir apenas com gestos, e somente quando requisitados pelos próprios alunos. O intuito dessa dinâmica é de fazer os estudantes pensarem por si mesmos e exercitarem os processos mentais de busca por respostas, seja buscando-as para suas próprias perguntas ou tentando responder aos questionamentos dos colegas. As habilidades de interpretação de texto e formulação de perguntas são treinadas à medida que é necessário entender e se fazer entender. Outro efeito no qual a dinâmica incorre é a diminuição da responsabilidade única do professor de trazer os conhecimentos para a aula, tornando possível que os alunos tragam suas próprias referências e aprendizagens à tona, criando um somatório que é sempre mais rico do que o que foi planejado.

Ao final da dinâmica de Roda Muda, o objetivo é que os alunos tenham organizado os conhecimentos à sua maneira e encontrem-se mais preparados para o início da elaboração do infográfico baseado no texto lido, estudado e discutido. 


\subsection{Protótipo}

$\mathrm{Na}$ aula seguinte à dinâmica de Roda Muda, os alunos trazem o primeiro protótipo de infográfico para análise mútua de seus pares, onde todo conteúdo de semiótica apreendido deve estar plasmado em uma página A4, com técnica livre.

A primeira versão contém a estruturação básica do pensamento e as primeiras tentativas de uma tradução própria do conteúdo, bem como os primeiros testes de como isso seria materializado, seja através de softwares digitais ou desenho manual.

Durante a aula os alunos compartilham os infográficos entre si e explicam seu processo; trocam opiniões sobre o método de organização e execução material; compartilham ideias e inspirações; falam sobre suas dificuldades durante o processo; verificam possíveis erros, discutindo os motivos e entendendo os diversos pontos de vista sobre um mesmo objeto. Professora e monitores também ajudam a corrigir erros de categorização, mas intervêm menos nos processos criativos. Nesse ponto o design de informação é especialmente acionado, porque é o infográfico que deve comunicar e não a explicação do estudante.

\subsection{Entrega do resultado final}

O produto final entregue (infográfico sobre o conteúdo aprendido e debatido em sala de aula impresso ou em PDF) é avaliado por professora e monitores com base tanto nos aspectos de design de informação quanto na exatidão das informações referentes ao conhecimento adquirido.

Os resultados são múltiplos e os alunos usam variados conceitos e metáforas para ilustrar e organizar a informação no infográfico. O uso de cores ajuda a categorizar os conceitos da tríade da semiótica e na maioria dos exemplos a leitura gráfica tem um fluxo definido. 


\section{CIDI $2017 \quad{ }^{8 \mathrm{~m}} \mathrm{CIDI}$

Figura 1: infográfico 1 (usado com a permissão de Eduardo Rabelo)
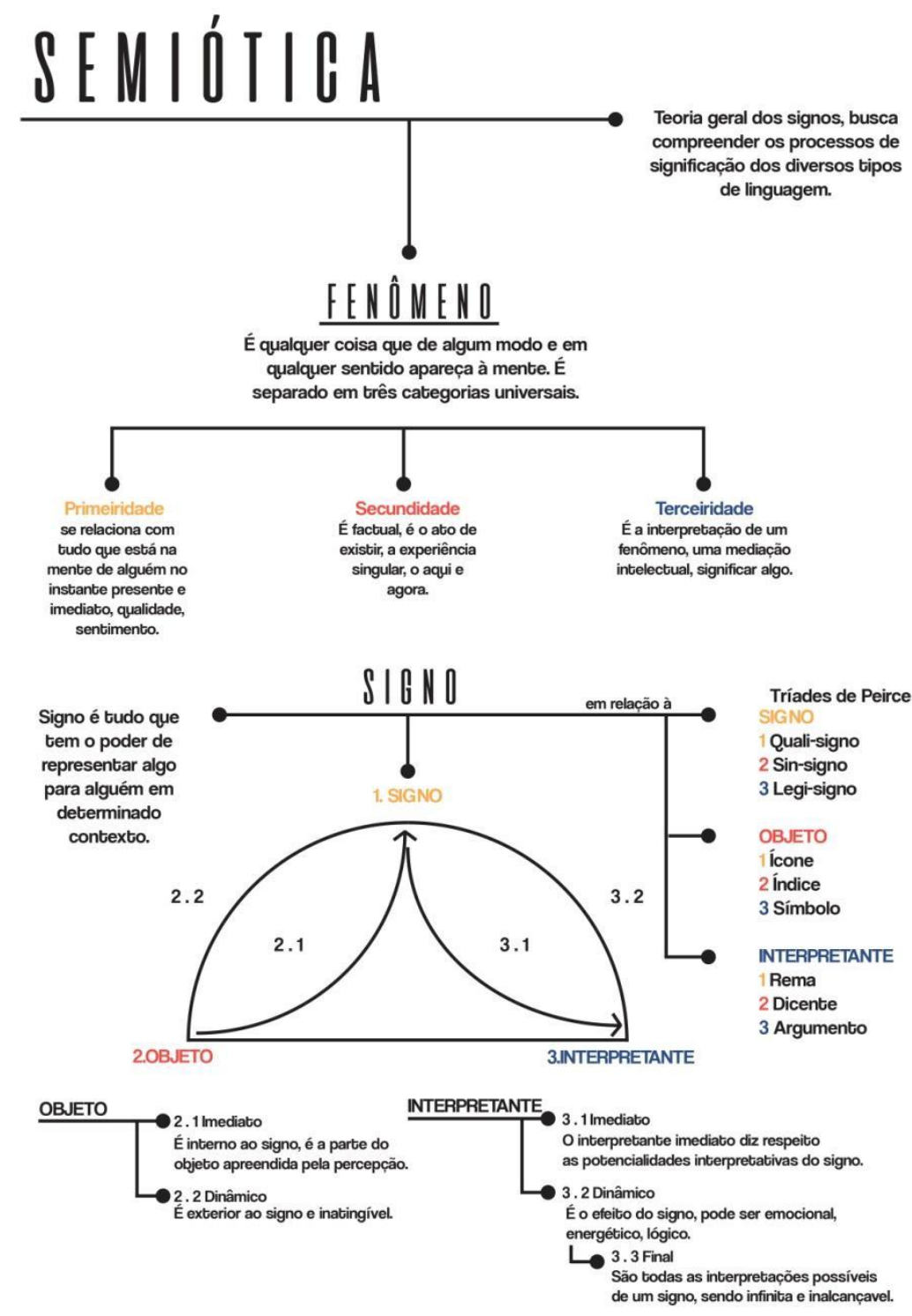

Este primeiro exemplo utiliza um esquema prático, com legissígnos indiciais, criando relações entre as várias partes do sistema de informações. Cores são associadas aos elementos triádicos, tanto para criar uma nova classe de informação dentro do infográfico, quanto para mostrar que as diferentes classificações estão associadas. O corpo do tipo varia hierarquicamente. O produto tem um aspecto pragmático e sucinto, e cumpre o objetivo de sintetizar as informações as quais se pretende passar.

Figura 2: Infográfico 2 (usado com a permissão de lanna Leal) 


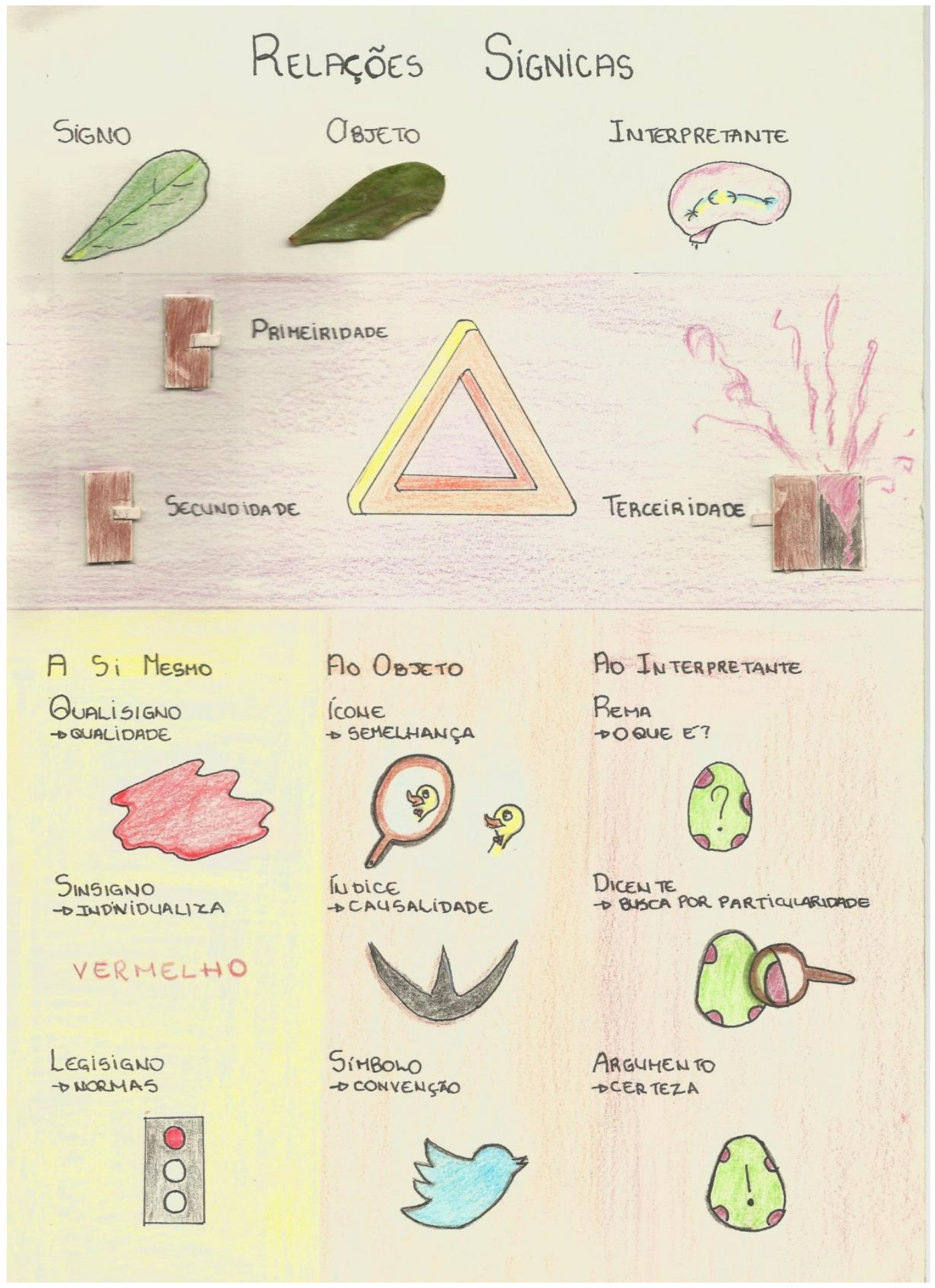

Apesar de simples em conteúdo a primeira vista, o exemplo atual destaca-se pela sua secundidade. A materialização se diferencia dos outros exemplos por sua execução manual, que permite interações e cria legissignos dentro da própria interface. A secundidade está presente, por conter um objeto real (folha) e por permitir que a porta (referente à secundidade) possa ser aberta no infográfico. A leitura é semi-sequencial e sempre tripartida entre os conceitos triádicos da semiótica, fenomenologia e relação sígnica, respectivamente. 


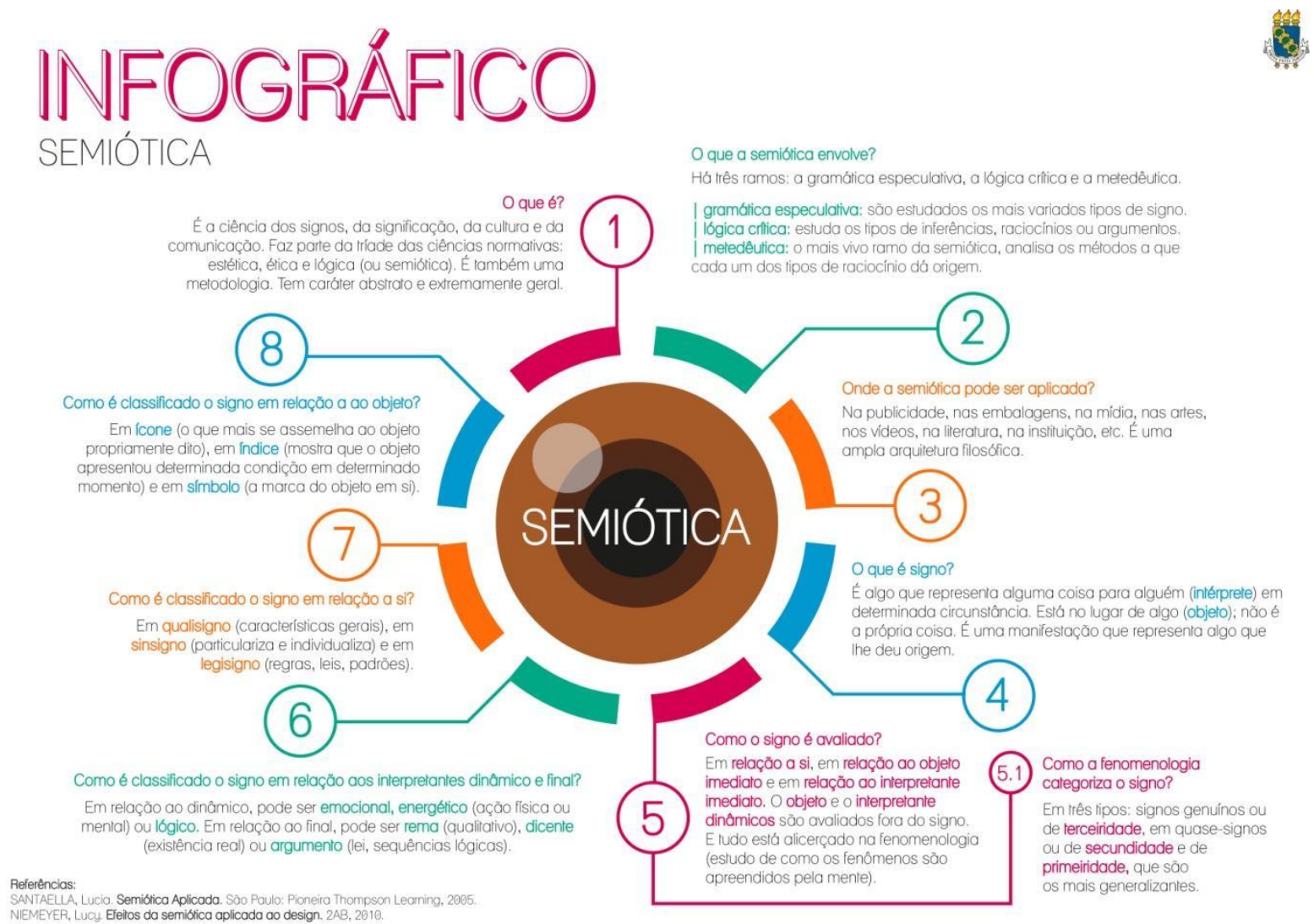

Figura 3: infográfico 3 (usado com a permissão de Rebeca Oliveira)

O exemplo se diferencia por sua arquitetura menos convencional. A presença do círculo remete a quali-signos que se relacionam com temas de ciclicidade, mostrando o conteúdo como um processo contínuo, ainda que sequencial. Os círculos centrais também possuem um aspecto iconográfico de um olho, que pode tanto figurar uma ironia ao sentido da palavra semiótica como evocar a amplitude da visão de mundo que ela pode oferecer. As cores usadas não possuem valor simbólico aparente como em exemplos anteriores, mas estimulam a visão e relacionam ênfases de texto aos números, além de tornar o infográfico mais chamativo. 


\section{CIDI 2017 intil

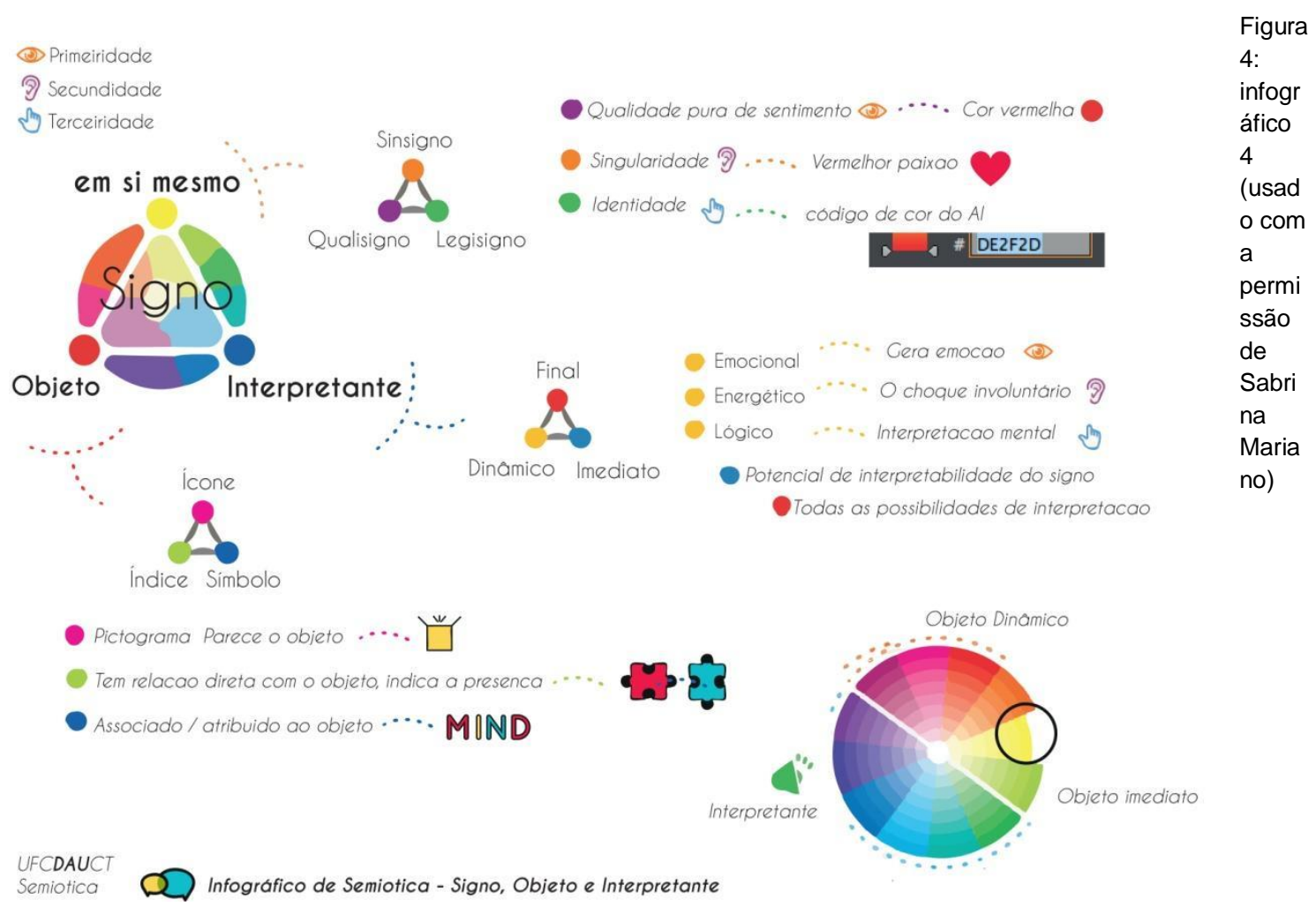

O exemplo se baseia fortemente em símbolos e índices que dão fluxo a uma leitura primariamente não-hierarquizada. As ilustrações e esquemas apresentam uma linguagem uniformizada para o produto. Nesse caso, as coressão quali-signo e o próprio objeto de análise na forma do círculo cromático, utilizadas como metáfora para explicar o conteúdo. A utilização das cores-objeto é rica suficiente para explorar muitos dos conceitos semióticos estudados.

\section{Considerações finais}

O procedimento apresenta resultados bastante positivos. Os alunos tiveram um primeiro contato com o conteúdo da Teoria Geral dos Signos de forma colaborativa e dinâmica. O incentivo às discussões e às intervenções se mostrou essencial e tornou o processo de aprendizagem mais rico ao incorporar, de forma constante, as vivências e experiências dos alunos, como o proposto pela metadisciplina.

No que diz respeito aos produtos do primeiro módulo, os estudantes tiveram liberdade para sintetizar o conteúdo da forma mais conveniente dentro de seus próprios critérios. Os 


\section{CIDI2017 ${ }^{g^{\mathrm{n}} \mathrm{CID}}$

infográficos resultantes denotam uma pluralidade significativa de soluções gráficas que indicam a capacidade adquirida pela turma de formalizar um pensamento complexo. Tanto a semiótica como o design de informação são utilizados como procedimento e resultado; o design de informação estrutura o conteúdo da lógica semiótica e a semiótica é utilizada como ferramenta para a compreensão da produção de signos, necessária a um design de informação eficiente.

Figura 5: Infográfico da metadiscplina, elaborado por Alexander Catunda Carneiro com a revisão dos autores durante a pesquisa.

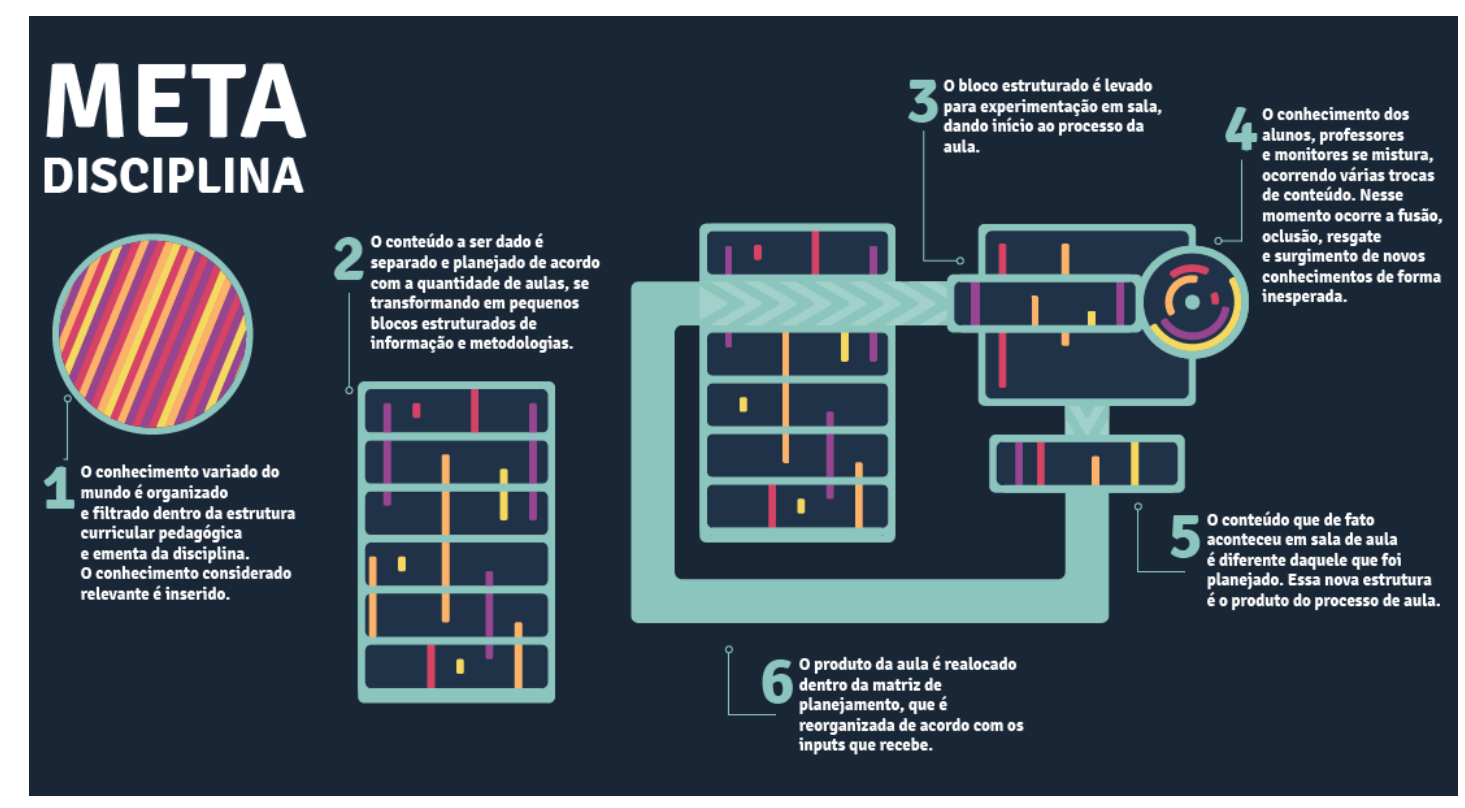

Acreditamos que este experimento contribui para o conjunto de abordagens metodológicas que a metadisciplina favorece. Esperamos que possa também contribuir para futuras iniciativas no ensino e prática do design, em que a construção de um espaço de aprendizagem implique a troca horizontal de conhecimentos como prioridade.

\section{Referências}

FRASCARA, J. Communication Design: principles, methods and practice. Canadá: Allworth Press, 2004.

FRASCARA. J. ¿Qué es el diseño de información? Buenos Aires:

Ediciones Infinito, 2011.

NIEMEYER, L. Elementos de Semiótica aplicados ao design. Rio de Janeiro: 2AB, 2007.

SANTAELLA, L. Semiótica aplicada. São Paulo: Pioneira Thomson Learning, 2008.

SHEDROFF, N. Information interaction design: a unified field theory of design. In: JACOBSON, Robert (ed.). Information design. Cambridge (MA): The MIT Press, 2000.

TOLEDO, R. F.; JACOBI, P. R. Pesquisa-ação e educação: compartilhando princípios na construção de conhecimentos e no fortalecimento comunitário para o enfrentamento de 
problemas. Educação \& Sociedade, Revista de Ciência da Educação. CEDES, Campinas, v. 34, n. 122: 155-173, jan.-mar. 2013.

TORRES, P. L. Laboratório on-line de aprendizagem: uma proposta crítica de aprendizagem colaborativa para a educação. Tubarão: Unisul, 2004.

TRIPP, D. Pesquisa Ação: uma Introdução Metodológica. Tradução Lélio Lourenço de Oliveira. Educação e Pesquisa, São Paulo, v. 31, n. 3, p. 443-466, set./dez. 2005.

\section{Sobre os autores}

Anna Lúcia dos Santos Vieira e Silva, PHD, UFC, Brasil <annalucialilu@gmail.com> Alexander Catunda Carneiro, UFC, Brasil <alexanderccarneiro@gmail.com> Lya Brasil Calvet, UFC, Brasil <calvetlya@gmail.com> José Rondney da Silva Mendonça, UFC, Brasil <rondneymendonca@gmail.com> 